\title{
The development of reading and spelling abilities in the first 3 years of learning Arabic
}

\author{
Wessam Mohamed - Thomas Elbert • Karin Landerl
}

\begin{abstract}
In a cross-sectional study, we investigated the development of fluent reading and spelling in the first 3 years of learning Arabic. The goals of our study were to: (1) validate suitable measures for fluent reading and spelling in the first 3 years of learning Arabic; (2) trace the developmental course of the relationship between fluent reading and spelling in the first 3 years of learning Arabic; and (3) evaluate potential gender differences in literacy skills and intelligence in the setting. The performance of 111 native Arabic students of the first three grades was assessed for one-minute reading, spelling and Raven's Coloured Progressive Matrices (CPM). Results showed significant developments in all measures across age. Reading fluency correlated highly with spelling measures. This association was more pronounced in the first but not in later graders. Boys performed better than girls as indicated by each of the measures used. Further analyses of first grade data indicate a potential role for the interaction of reading, gender, and CPM on the spelling scores. Based on our findings, we suggest that, in the Arabic orthography, both alphabetic and orthographic skills are adopted first for spelling. However, developing orthographic strategies in spelling does not guarantee the same transition to fluent reading processes as children in the first 3 years of learning Arabic are not yet exposed to unvowelized scripts forcing the reader to rely on orthographic strategies in order to read fluently. Moreover, our results indicate a potential role of visualization and spatial abilities in the relationship between fluent reading and spelling in the early stages of literacy acquisition, but not in later grades.
\end{abstract}

W. Mohamed · T. Elbert

Department of Psychology, University of Konstanz, P.O. Box D23, 78457 Konstanz, Germany

W. Mohamed $(\square)$

Department of Psychology, University of Fayoum, Al Fayoum, Egypt

e mail: wessam psy2010@yahoo.com

K. Landerl

Department of Psychology, University of Tübingen, Tübingen, Germany 
Keywords Phonological · Orthography $\cdot$ Semitic $\cdot$ Arabic $\cdot$ Fluent reading · Spelling $\cdot$ Gender-differences

\section{Introduction}

The start of formal education is a crucial period for the acquisition of literacy. From the pedagogical point of view, it is significant to know more about the development of reading and spelling during this phase (Leppänen, Niemi, Aunola, \& Nurmi, 2006). Only recently, word reading fluency has moved from being a neglected aspect of reading to being a popular topic in the field of reading research (Landerl \& Wimmer, 2008). Additionally, the magnitude, consistency, and stability of gender differences across time have recently been questioned. While the relationship between reading and spelling abilities as well as the existence of differences between boys and girls in various cognitive and educational abilities among school students in the United States and Europe has become reasonably well established, little empirical research has been reported for Arabic backgrounds. Therefore, we wanted to explore the developmental course of fluent reading and spelling during the first 3 years of learning Arabic. More precisely, we tried to examine the relationship between fluent reading and spelling. According to Taouk and Coltheart (2004), literacy acquisition is highly likely to be dependent upon the nature of the writing system which the child seeks to master. Hence, the special nature of Arabic orthography should be considered carefully in any discussion of a comprehensive theory of how children learn to read and spell.

Arabic orthography

Arabic is a Semitic language containing 29 consonants and 8 vowels. The Arabic writing system is primarily consonantal with short vowels represented as superscripted. This makes the Arabic writing a syllabic one (Hanna \& Greis, 1972). All diacritics are regularly mapped onto the phonemes they represent (Saiegh-Haddad, 2007). There is a predictable sound-symbol correspondence between the letters and their sounds if the Arabic text is presented by adding diacritics, or more specifically a pointing/vowelization system. Texts are typically written in vowelized so-called shallow/transparent orthography for beginning readers, and in unvowelized deep orthography for more advanced readers. In many cases, an Arabic word consists of only root consonants and short vowels. The additions of short vowels or more complex affixes (phono-morphological information) help to provide both semantic and phonological information to the root. Moreover, vowelizing the end of a word indicates its grammatical function. Paradoxically, the diacritical system in Arabic itself, although useful in decreasing phonological ambiguity, might constitute a source of difficulty for the beginning reader while mastering Arabic word decoding skills necessary for the phonological (non-lexical) route. When text is not vowelized, like in modern written and printed literary scripts, the reader has to depend on context and/or morphology and syntax and early exposure to print (e.g., Abu-Rabia, 2000). The majority of Arabic letters 
differ in form depending on their position in a word or in a smaller graphemic unit (connected with a preceding letter, connected with a following letter, connected with both letters; and not connected) (for a summary, Abu-Rabia, 1997, 1998, 2001, 2002; Elbeheri \& Everatt, 2007; Taouk \& Coltheart, 2004). Some scholars have considered Arabic as a case of diglossia, a term according to which the spoken and the written language are substantially different in terms of vocabulary, phonology, syntax, and grammar, which means that these children read a language with which they are unfamiliar (Abu-Rabia, 2000; Saiegh-Haddad, 2003, 2004, 2007). However, the term Arabic diglossia is not universally accepted (see e.g., El-Hassan, 1979).

Learning to read and spell

Early models of literacy acquisition proposed that children would acquire the different subcomponents of reading and spelling in a sequence of stages. According to these models, young children first go through a stage called a logographic (Frith, 1985), discrimination-net learning (Marsh \& Desberg, 1983) or pre-alphabetic (Ehri, 1997). During this visually-based stage, children begin to associate words with pictures or situations and recognize words based on salient graphic features. According to Frith (1985), a logographic skill is adopted first for reading, and only later for spelling. This explains how children read successfully familiar labels and words, while at the same time producing scribbles that superficially resemble cursive writing but lack any letter details (Ehri, 1997). The next alphabetic stage starts when children rely more on grapheme-phoneme correspondence (GPC) rules, a letter-sound by letter-sound analysis, whereby decoding skills are developed. According to Frith (1985), this skill is believed to be used first for spelling, then for reading as here the sequential writing down of each letter makes it obvious to the child that these letters have a systematic relationship to the sounds of the spoken word. At last, children start to tackle the orthographic stage when they automatically recognize spelling units, especially the morphemic parts of words, while reading. Thus, in Frith's model spelling acts as a kind of pacemaker for the alphabetic stage and reading is the pacemaker for the orthographic stage.

It is important to note here that some researchers, contrary to Frith, argue that these stages do not emerge out of steps. Instead, they suggest that performance in reading and spelling influence each other over the distinct stages of literacy development, and the direction of this influence changes over time (for review, Ehri, 1997; Snowling, 2000). Moreover, different writing systems show different and unique linguistic characteristics that affect the acquisition of literacy skills in different languages (Abu-Rabia, 1997, 2001, 2002). For instance, Wimmer and Goswami (1994) have pointed out that while it is possible to argue that the sequence of stages, proposed by Frith (1985), may be characteristic of learning to read English, which has a relatively opaque orthography, this sequence may not apply to learning to read a highly transparent orthography such as German. The authors explained that in German, the mapping from graphemes to phonemes is largely consistent, so that an adaptive strategy for young German readers would be to use grapheme-phoneme translation from the beginning of reading, omitting an initial 
stage of logographic access (Wimmer \& Goswami, 1994). Further evidence has been given from Arabic which is characterized by a unique orthography in terms of the relationship between consonants and vowel diacritics, the presence of positionspecific variants of letters and the transition to a phase where one is able to read without them. In the early stages, children rely on a letter-to-sound conversion of print rather than whole-word recognition. The former process can only be fulfilled when the Arabic script is presented in a vowelized way, (Taouk \& Coltheart, 2004) which facilitates early decoding, (Share \& Levin, 1999), reading accuracy and reading comprehension among beginning and more advanced Arabic learners (for a summary see Abu-Rabia, 1997, 2001, 2002; Elbeheri \& Everatt, 2007; Taouk \& Coltheart, 2004). This in turn accelerates an earlier transition from the phonologicalrecoding (alphabetic) phase to the orthographic phase. Importantly, in Azzam's (1993) study, profiles of reading and spelling errors of 611 years old normally developing children showed that in Arabic reading, the visual-based logographic skills are adopted first for reading, while alphabetic and orthographic skills are adopted first for spelling. Additionally, to acquire basic literacy in Arabic, Azzam suggests that the use of an alphabetic strategy may be enough for competent reading, while competent spelling requires at least the usage of orthographic strategies if not the grammatical/semantic phase. As a result, it is predicted that the interdependence between reading and spelling diminishes in later stages of literacy acquisition in Arabic (Azzam, 1993).

According to many theorists, the two components of literacy, reading, and spelling, are closely linked. Overall, experimental and correlation studies suggest that both reading and spelling contribute to and facilitate each other. Empirical evidence shows those correlations between word reading and spelling in English, for example, are rather high, ranging from .77 to .86. Such high correlations, again, indicate that very similar processes are measured in these tasks even if different materials for reading and spelling were used. This is true among younger (first to six graders) as well as college students (for a review, see Ehri, 1997). These findings, found in the English context, suggest that not only a single orthographic lexicon is, probably, used for reading and spelling processes (for a summary, see Leppänen et al., 2006; Lerkkanen, Rasku-Puttonen, Aunola, \& Nurmi, 2004), but also that both reading and spelling require in parts the same phonological and visual skills.

Although the association between reading and spelling development is strong, reading is commonly thought to precede spelling in the literacy acquisition of alphabetic orthographies (Leppänen et al., 2006). This is probably due to the fact that spellers need lexical knowledge to ensure orthographically correct spelling, while readers may rely on partial orthographic knowledge of those words in the text while reading (Abu-Rabia \& Taha, 2004). Evidence has been provided for German, an asymmetric consistent orthography, in which the recognition of orthographic representations required in reading is easier than full retrieval of the correct letter sequence from orthographic memory required to ensure correct spelling (Moll \& Landerl, 2009).

Moreover, throughout their primary years, the adopted reading strategy is likely to strongly affect spelling competence. During the first and second years of reading instruction, with various extensions into the third year, children lay down mental 
images or templates of words, morphemes, and syllables in memory that will persist for life. These templates are most often called Visual Orthographic Image (VOI). Insufficient storage of VOIs leads to spelling failure (Ehri \& Wilce, 1982).

Processes of reading and spelling in Arabic have been derived by data collected from samples with an age range of 830 years (Abu-Rabia, 1995, 1997). Some studies were based on data derived from bilingual children: Arabic-Hebrew (AbuRabia, 2001) and Australian-Lebanese (Taouk \& Coltheart, 2004). To our knowledge, except for the analysis of reading and spelling errors in 611 years old Arab children in Azzam's study (1993), there are no other attempts to study the relationship between reading and spelling abilities at the very early stages of learning Arabic in a monolingual sample. In addition, only reading fluency in Arabic orthography has so far only been investigated for pseudowords (SaieghHaddad, 2005).

\section{Gender differences}

With respect to gender differences in cognitive abilities, two opposing positions have been taken. One viewpoint has been asserted by Feingold (1988), Hutt and Hughes (2004), and Richardson (1997), who suggest different patterns of gender differences in abilities as a result of socialization and cultural influences which shape a gender-typed behavior. An opposite view has been presented by Kimura (1999), who postulates that gender differences in cognitive abilities are significantly biologically determined, largely by hormonal influences and genetic factors (for a summary, see Khaleefa \& Lynn, 2008). If true, we would expect identical genderdifferences in different cultures.

In addition, Lynn $(1994,1999)$ has proposed a developmental theory for gender differences in intelligence, in general, which he later applied to the results of Raven Progressive Matrices. He postulates that both boys and girls mature at the same rate up to the age of 7 years. At the age of 8 or 9, the growth of girls accelerates and remains advanced until 1415 years. At 1516 years the physical growth and the intelligence of girls slows relative to boys.

While a rich literature on gender differences in reading exists, very little is known about the development of spelling abilities. However, assumptions about spelling might be drawn from reading research. Accordingly, girls usually outperform boys in verbal and oral as well as reading tests (Allred, 1990; Horne, 2007), a view that is supported by epidemiological investigations of gender differences in the United States, Germany, New Zealand, and the UK (reviewed by Chiarello et al., 2009). Additionally, reading disabilities are certainly more frequent in boys than in girls (Rutter et al., 2004). On the other hand, a number of reports point to less simple relationships. Using a simple spelling test, Millar and Barber (1981) found that males made significantly more errors than females, but there were no significant gender differences in another judgment task that emphasized the knowledge of phonological rules related to spelling. Many studies of more normal reading children have not found strong gender differences. Hyde and Linn (1988) conducted a large-scale meta-analysis of studies that examined gender differences in general verbal abilities. They suggest that the overall magnitude of gender 
differences in these samples is quite small, especially when excluding dyslexic subjects from the analyses. Further, computerized assessments of literacy skills did not detect the established gender effect, while girls performed better in paper and pencil versions of the same tests (Horne, 2007).

In the current analysis, we describe the developmental course of fluent reading and spelling abilities in the first years of learning Arabic. Three goals were set for the present study: (1) develop and validate tests of fluent reading and spelling for the first 3 years in primary school; (2) investigate the relationship between reading and spelling in the first 3 years of learning Arabic; and (3) examine potential gender differences in literacy skills and fluid intelligence, including reasoning and visualization skills as measured by Raven's Coloured Progressive Matrices in the first 3 years of learning Arabic.

\section{Method}

\section{Participants}

Altogether 111 Arab children in grades 1 through 3, who were enrolled in a private school in Egypt, were randomly recruited ${ }^{1}$ for the current study. There were 34 children from the first grade (56\% male, mean age $=5.89 \pm .43 \mathrm{SD}$ years), 30 children from the second grade $(60 \%$ male, mean age $=6.98 \pm .58$ SD years) and 47 children from the third grade $(60 \%$ male, mean age $=7.93 \pm .40 \mathrm{SD}$ years). Assessments took place 3 months after the beginning of the school year. Three children were excluded from the study as they had hearing abnormalities, severe visual difficulties, neurological disorders, or had not attended kindergarten. Parental consent forms were sent home and the voluntary consent of children was also required.

\section{Tools}

The following literacy measures were developed for the current study: a one-minute reading test (words and pseudowords) and a spelling test.

One minute reading test

A one minute reading test has been proven as an efficient way to assess and evaluate the reading performance, especially in orthographically transparent languages (Willburger \& Landerl, 2009). The Arabic script serves as a transparent orthography when presented in a vowelized form. Therefore, we used a one minute reading test which was designed to provide an assessment of accuracy as well as the fluency of the reader. The test provides a score for correct words to be read aloud in only one minute and was modelled after the Ein-Minuten Leseflüssigkeitstest designed by Willburger and Landerl (2009). Two sheets were presented to the child including

${ }^{1}$ Children were randomly selected based on alphabetically ordered lists of classes. 
either words or pseudowords. Each sheet contained 136 items to be read aloud, which were presented in eight columns in terms of word frequency, length, or difficulty level. Practice items were given to the participants before reading the test items. Both sheets were presented in vowelized Arabic form. A test retest method (second assessment was 1 month later) for 109 children showed reliability coefficients of .95 and .73 for word lists and pseudoword lists, respectively, $p<.01$. The test could be proven to be valid as it distinguishes children with different reading abilities: good, average and poor readers as rated by teachers. Test performance was highly consistent with teacher's categorization of good, average, and poor readers, in a random sub-sample of 83 students. ANOVA showed a significant GROUP effect, for the word reading test $F(2,81)=5.80, p<.01$ ), and pseudowort reading test $[F(2,81)=5.43, p<.01]$, respectively. Post hoc comparisons (Scheffé-Test) showed that poor readers, as estimated by teachers' ratings, received the lowest scores on word and pseudoword lists, respectively, (mean $=2.6$ and 1.2) as compared to average readers (mean $=9.6$ and 4.5 ) who in turn received significantly lower scores as compared to good readers (mean $=23.2$ and 12.6; all $p$-values $<.01)$. Moreover, scores of the teachers given to the children based on their performance on scholastic achievement in Arabic was positively correlated with the scores of the children on our reading test, $(r=.35$ and $r=.34 ; p<.01$ for word reading and peusoword reading respectively).

\section{Spelling test}

The test was designed based on the Salzburger Lese- und Rechtschreib-Test (SLRT) by Landerl et al. (1997). The final version of our test consisted of 36 sentences with 36 target words. Only target words have to be written. Sentences were read aloud with a consideration to the external vowelization (alaamaat iaraab). The score of the correct number of correctly transcribed graphemes $(\max .=204)$ was determined following May's (2002) Hamburger Schreib-Probe (HSP). Criteria for Arabic spelling in the first 3 years had been thoroughly studied as provided by the teacher's guide for teaching Arabic in those years. Accordingly, target words for the test were selected based on the specific skills that students should master in each grade. A test retest method (the second assessment was 1 month later) for 43 children showed a reliability coefficient of $.92, p<.01$ for grapheme accuracy. Again, the test proved to be valid. It showed the ability to distinguish between good, average, and poor spellers, based on teachers' observations and ratings of a random sub-sample of 84 students. An ANOVA showed a significant GROUP effect $[F(2$, $82)=12.28, p<.01]$. Post hoc comparisons (Scheffé-Test) confirmed that poor readers as estimated by teachers' ratings received the lowest scores $($ mean $=68.4$ ) as compared to average spellers (mean $=92)$, who in turn received a significantly lower score than good spellers (mean $=149.91$ ); $p<.01$ ). Moreover, scores of the teachers given to the children based on their performance on scholastic achievement in Arabic was positively correlated with the scores of the children on our spelling test, $(r=.47 ; p<.01$ for word reading and peusoword reading respectively). 
CPM: Raven's colored progressive matrices

The Colored Progressive Matrices (CPM) were constructed in the 1940s as a suitable test for children aged 511 years, and were thus designed as an easier version of the Standard Progressive Matrices. The CPM comprises 36 items divided into three sets of 12 (set A, Ab, and B). Within each set, items (which are brightly colored to attract and maintain children's attention, except the very last few items in set B which are presented as black-on-white) are ordered in terms of increasing difficulty. In each test item, a candidate is asked to identify the missing segment required to complete a larger pattern. The CPM has commonly been employed as an estimate of the non-verbal component of Spearman's g-factor in research, but more recently as the purest measure of fluid intelligence. Since no normative scores for CPM were available for us in Arabic backgrounds, we used raw scores for statistical analyses (Raven, 2000; Raven, Bulheller, Court, Häcker, \& Raven, 2006).

\section{Procedure}

The tests were administered during three sessions. In the first session, the spelling test was group-administered in the natural school conditions, which had been highly controlled to prevent cheating. Children were instructed to listen to the teacher who uttered a sentence and then dictated the target word in correctly vowelized spoken Arabic. Then children had to write down the target word. Once the dictation was completed, the sheets were collected. Subsequently, the one minute reading test was individually administered in a quiet place, namely the library. Children were encouraged to read aloud as fast as they could by giving them a practice for both words and pseudowords. They were reminded to pay attention to diacritics as they would help them to read the vowelized script correctly. Exactly one minute as measured by a stop watch was given for each sheet and numbers of correctly read words and pseudowords per minute were scored separately. The last session in which CPM was individually administered was on a separate day. Children were told to play a little puzzle with the examiner. All sessions were administered in the early morning so as to guarantee attention and stable performance on the tests. The duration of sessions ranged from 50 to $75 \mathrm{~min}$.

The statistical analysis was carried out using SPSS16 and STATISTICA6 for Windows. ANOVAs, $t$-tests (for normally distributed variables) and WilcoxonRank tests for independent samples (for not normally distributed variables) were performed to determine differences between age groups and effects of gender. Correlation coefficients were calculated between psychometric measures and age.

\section{Results}

Table 1 presents reading fluency, spelling and CPM means and SDs for grades 13 . Moreover, the box plots for word and nonword reading, spelling and CPM presented in Fig. 1 illustrate an expected increase of all psychometric scores with the age/ grade level of school. 
Table 1 Descriptive statistics for all measures

\begin{tabular}{lccr}
\hline Measures & \multicolumn{3}{l}{ Grades } \\
\cline { 2 - 4 } & $1(N=34)$ & $2(N=30)$ & $3(N=47)$ \\
\hline Word reading (item/min) & $4.9(4.62)$ & $15.9(9.93)$ & $35.7(18.97)$ \\
Pseudoword reading (item/min) & $2.97(3.44)$ & $7.73(6.06)$ & $17.98(12.00)$ \\
No. correct for graphemes (spelling) & $84.41(49.52)$ & $144.67(37.59)$ & $178.02(31.09)$ \\
No. correct items for CPM & $14.09(4.30)$ & $17.90(4.99)$ & $19.08(5.03)$ \\
\hline
\end{tabular}

Values enclosed in parentheses represent SDs. Column and row means and SDs are also provided

Overall, there were statistically significant differences in all literacy measures (word reading, pseudoword reading and spelling) across the three grades. Third graders outperformed second graders, whose means were significantly higher than first graders, $p<.01$. Means of CPM scores were 13.5, 17.5 and 19 for 6,7 and 8 years old, respectively. Comparing these age scores to the British norms (Raven, 2000), our sample showed normal development with no signs of mental retardation. A repeated measure ANOVA was conducted to determine the lexicality effect. Word Type (word, pseudoword) served as a within factor for the whole cohort. Results showed a significant effect for LEXICALITY, $[F(1,110)=118.52$, $p<.01)]$.

Correlations between the psychometric measures and age are presented in (Table 2). The substantial positive correlations between reading and spelling in Arabic ranged from .88 to $.92, p<.01$. There were also significant positive correlations, ranging from .48 to $52, p<.01$, between CPM and all literacy skills. Furthermore, there was a strong correlation between word and nonword reading in the whole cohort $(r=.92, p<.01)$. A combined score of the number of correctly read words per minute and correctly read pseudowords per minute (Reading) was subjected to further statistical analysis. The scatterplot in Fig. 2 illustrates the relation between spelling and reading fluency scores (correct word/min. + correct pseudoword/min.). Obviously, there are no fluent readers with a poor spelling score, whereas fluent reading may considerably vary for those with good spelling scores. Fluent reading skills may further increase with age, when spelling has reached a saturation, which implies that adequate spelling develops earlier than good fluent reading.

To investigate potential gender differences in the psychometric tests, a two-way ANOVA was used to determine the effect of AGE and GENDER on the CPM scores. Results showed a significant main effect of AGE and an AGE*GENDER interaction $[F(2,98)=11.24, p<.01] ;[F(2,98)=3.07, p<.05]$; respectively. No significant effect was found for GENDER $[F(1,103)=.38 p<.05]$. Post hoc Bonferroni tests showed that first graders scored significantly lower than both second and third graders; $p<.01$. No significant differences were observed between second graders and third graders. A male advantage was observed only in the first graders, $p<.05$. Furthermore, $p$ values were computed for either $t$-tests or Wilcoxon Rank tests for independent samples to assess gender differences in the literacy skills. Again, only boys in first grade outperformed girls $(p<.05)$. 

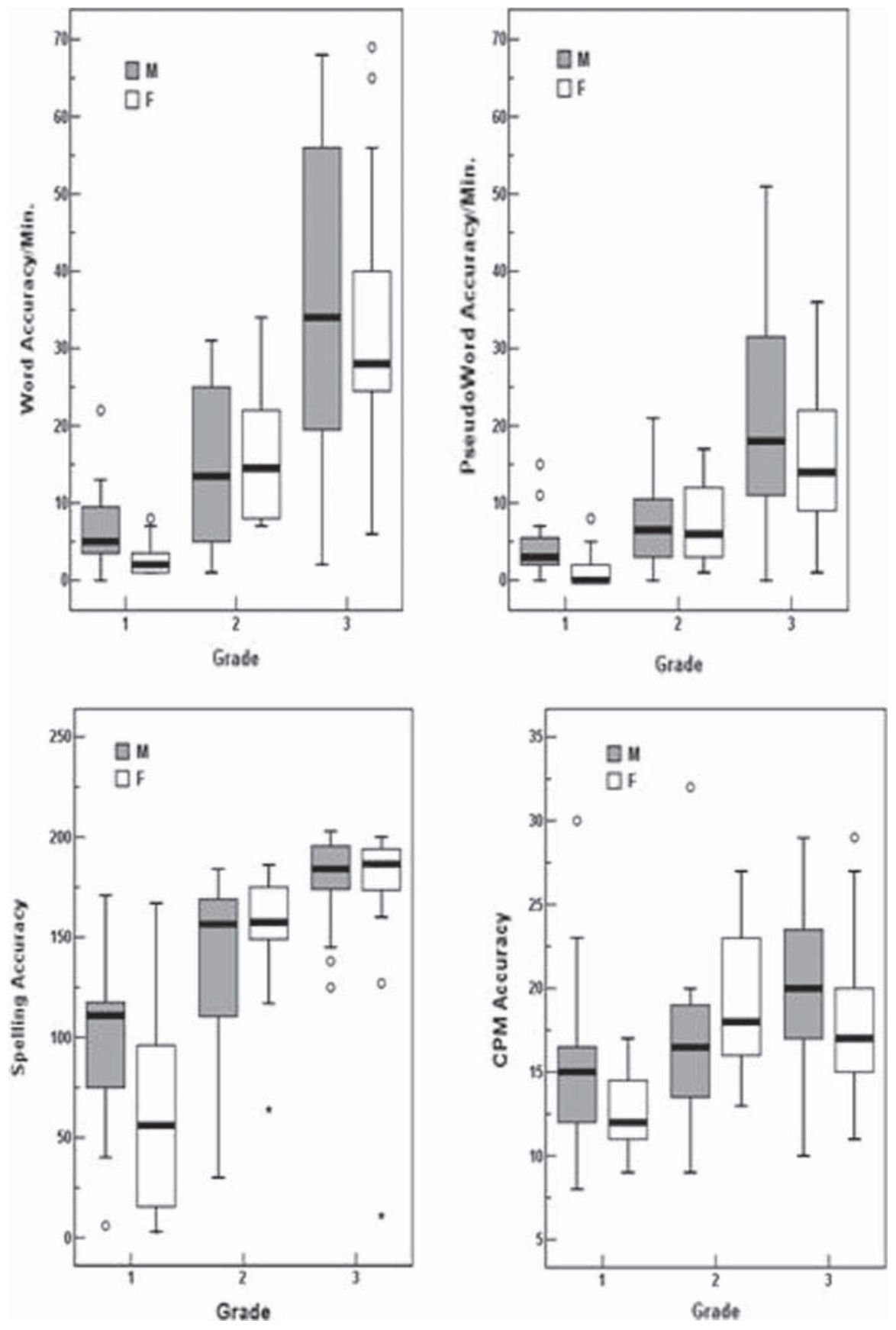

Fig. 1 Box plots of the first 3 years for word and pseudowords accuracy/min, for the reading test, for the grapheme spelling accuracy and for the CPM with consideration of gender differences. "M" refers to male, while "F" stands for female 
Table 2 Spearman rank correlational analyses for the whole cohort

Note: $r$ values equal to or greater than .43 are significant at the .01 level

\begin{tabular}{llll}
\hline Age & $\begin{array}{l}\text { No. correct } \\
\text { for CPM }\end{array}$ & $\begin{array}{l}\text { Word } \\
\text { reading }\end{array}$ & $\begin{array}{l}\text { Pseudoword } \\
\text { reading }\end{array}$ \\
\hline
\end{tabular}

No. correct for CPM $\quad .52$

Word reading $\quad .79 \quad .52$

$\begin{array}{llll}\text { Pseudoword reading } & .65 & .48 & .92\end{array}$

$\begin{array}{llllll}\text { No. correct for } & .77 & .48 & .91 & .88\end{array}$

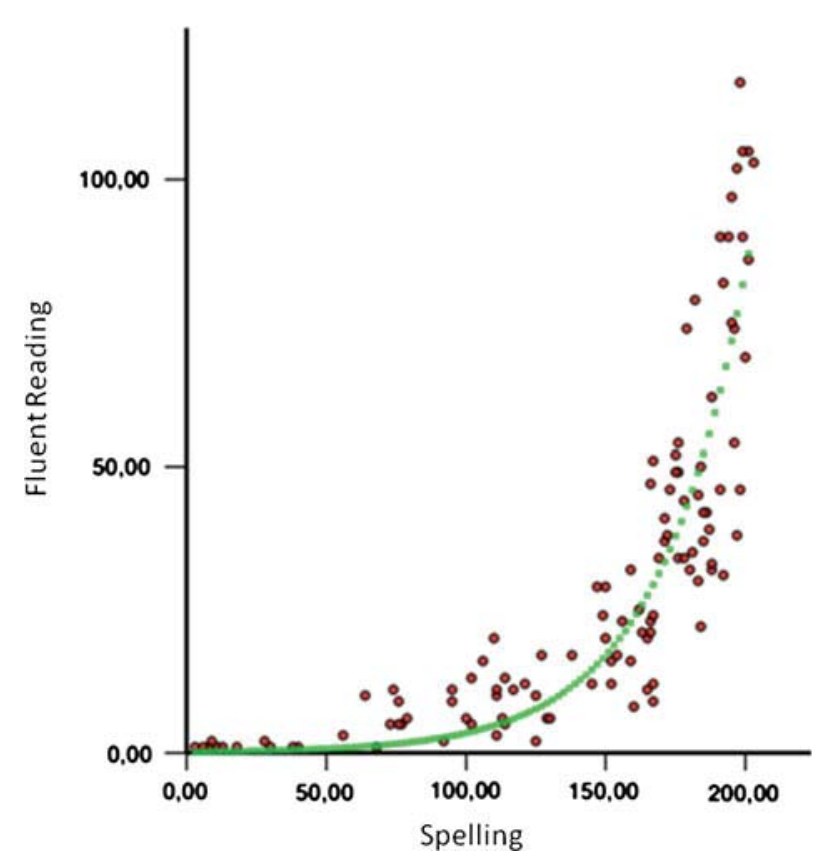

Fig. 2 The scatter plot illustrates the relationship between spelling and reading abilities. The lines indicate a significant exponential trend for the whole cohort. $R$ square $=.84$

The observation of a potential gender difference among first graders may indicate the importance of visualization skills as measured by the CPM in forming the observed association between fluent reading and spelling. Therefore, we further investigated first graders by computing an ANCOVA to test if gender differences in the spelling measure would persist after controlling IQ and reading level. Using a $3 * 1$ covariate model, GENDER served as a fixed factor, while READING and CPM were chosen as covariates. The results showed a significant effect only for the interaction of READING*CPM*GENDER on spelling, $[F(2,27)=9.71, p<.01]$, but no significant effects were found for READING, $[F(1,33)=.46]$; GENDER, $[F(1,33)=.18, p=.68]$ or for GENDER*CPM, $[F(1,33)=1.87, p=.18]$. A trend has been indicated for the effect of $\operatorname{CPM}[F(1,33)=3.91, p=.06]$. 


\section{Discussion}

Overall, the findings of the current study indicated that normally developing children in grade 1 through 3 are characterized by: (a) an increase of the ability to rapidly name words and pseudowords, to correspond each phoneme to its grapheme and to develop their visual and spatial abilities; (b) an association between fluent reading and spelling in earlier grades which diverges later as spelling develops earlier than fluent reading; (c) an observed male advantage of literacy skills as well as visualization abilities, as measured by CPM, only in first graders, and (d) a reliance on visual strategies which likely mediate the interplay between fluent reading and spelling in its early stages of literacy acquisition, namely the first grade, but not in later stages.

Development of the relationship between reading and spelling

Normally developing Arab children showed a smooth increase in their fluent reading performance as a function of age/grade level. A foundational processing factor, namely fluency in word identification has been suggested as an indicator of overall reading competence (Cohen-Mimran, 2009) and as a critical prerequisite for adequate reading comprehension (Prefetti \& Hart, 2001) as well. Taking into consideration that Arabic scripts were presented in a vowelized way in our literacy measures, patterns of results similar to languages with invariant GPC are, therefore, expected. Our results are similar to a group of longitudinal studies, which aimed to trace the development of reading fluency and/or spelling in transparent orthographies such as German, Dutch, or Finnish. A high stability of reading fluency across ages was observed in Finnish children as well as in German children. Importantly, word recognition speed was a relevant and highly stable indicator of reading skills and the only indicator that discriminated reading skill levels in consistent orthographies (for a summary, see Landerl \& Wimmer, 2008).

Further, we compared the fluency rate of first graders in Arabic with the previous results of Seymour, Aro, and Erskine (2003) in which they compared the reading fluency rate of first graders in European orthographies. As they have operationally defined fluency rate as a speed of $<2.25 \mathrm{~s} /$ item on the word list reading task, Arabic speaking children showed a relatively low fluency rate. This might be due to the fact that despite its simple syllabic transparent orthography, Arabic is a multi-syllabic word based language (Saiegh-Haddad, 2004). This, in turn, adds some complexity to its literacy acquisition and may lead to a relative reduction in fluency compared to simple shallow orthographies (Seymour et al., 2003).

Interestingly, there is a high correlation between word and pseudoword reading fluency in the whole cohort. This is consistent with the results of Thomson, Crewther, and Crewther (2006), who report a high correlation between words and pseudowords for children in the first 4 years of learning English. In our study, this correlation could be explained by the fact that lists of words and pseudowords were graded in terms of familiarity and complexity. Therefore, it is possible that some of the pseudowords, constructed by replacing one letter of a familiar word, were accessed through the direct lexical route and recognized directly as words. The 
reliance on the direct lexical route was again observed by the lexicality effect (reading more words than pseudowords) in the whole cohort.

Consistent with literature on European languages, our results show high correlations between reading and spelling measures in normally developing Arab children, suggesting a single orthographic lexicon used for reading and spelling processes (for a summary, see Leppänen et al., 2006; Lerkkanen et al., 2004). Stahl, Pagnucco, and Suttles (1996) showed that success in reading is associated with spelling success during the first grade: Good readers always tended to be good spellers, a conclusion that is strongly supported by our results, presented in Fig. 2. Our results also showed a divergence between reading and spelling skills depicted by the earlier development of spelling skills compared to good fluent reading, supporting Frith's argument (1985) that spelling is the pacemaker of the alphabetic phase, and reading comes later.

In Arabic, the dissociation between reading and spelling can be expected to be most pronounced during the transition from the logographic to the alphabetic phase (Abu-Rabia \& Taha, 2004). Azzam (1993) postulated that the acquisition of both basic literacy and competent reading, defined by reading accuracy, requires the use of an alphabetic strategy. Spelling, on the other hand, requires at least the usage of orthographic strategies if not the grammatical/semantic phase as well. As a result, it is plausible here that the interdependence between reading and spelling diminishes in later stages of literacy acquisition in Arabic (Azzam, 1993). Further, our results showed that adequate spelling develops earlier than fluent reading. Hence, we suggest here that while alphabetic strategies could be sufficient for accurate reading, orthographic strategies are a prerequisite for fluent reading. Such strategies develop earlier in the Arabic orthography as it is presented in a vowelized way for children in the first three grades of its learning. Accordingly, we assume that fluent reading develops later when diacritics are omitted and children have to rely on orthographic strategies. Similar to this view were the findings of Cohen-Mimran (2009) which showed that in order to read unpointed Hebrew texts fluently, children had to integrate their phonological, orthographic, semantic, syntactic, and morphological processes. Another possible explanation for the early development of spelling compared to fluent reading could be attributed to the phonological distance between the spoken and the literary/standard representations of Arabic language, referred to as Arabic diaglossia (see Saiegh-Haddad, 2003, 2004, 2005). Accordingly, this might have an impact on literacy acquisition, namely reading, as some letters represent standard phonemes that are not familiar to kindergarten and first-grade children in their spoken form. ${ }^{2}$ Moreover, awareness for standard phonemes was also found to be indirectly related to pseudoword reading fluency in Arabic (SaieghHaddad, 2003). However, by the end of the first grade, the isolation of diglossic phonemes does not seem to be as strongly related to pseudoword fluent reading, suggesting a potential role for other cognitive factors such as the speed of converting graphemes to phonemes and memory (Saiegh-Haddad, 2005).

\footnotetext{
${ }^{2}$ An example of this is the phonological representation of standard/ð/as/d/in spoken Arabic.
} 
Gender differences

$C P M$

Our data revealed the expected age/grade effect for CPM scores. CPM has been regarded as one of the typical tests of GF or fluid intelligence (Jensen, 1998; Mackintosh, 1998). Our results for Arabic children are consistent with previous studies on European and American children. Cotton et al. (2005) observed an age effect for Australian children aged from 6 to 11 years with the greatest mean differences between 6 and 9 years of age. In Arabic backgrounds, Khaleefa and Lynn (2008) administered CPM on a representative sample of 986 Yemeni children whose ages ranged from 6 to 11 years. In relation to British norms, their results showed an advantage of younger children 67 years on visualization items, but not of older children on abstract reasoning items. These results were previously reported for Syria and the United Arab Emirates (Khaleefa \& Lynn, 2008).

Taking a closer look at gender differences, our results showed an advantage for boys over girls on CPM scores, which was, however, only pronounced in the first grade and not in later grades. It has been proposed that the progressive matrices are not a pure measure of reasoning ability, as has been frequently asserted, but also a measure of visual-spatial capabilities, namely, in CPM and later items of Standard Progressive Matrices (SPM) (Lynn, Backhoff, \& Contreras-Niño, 2004). Importantly, studies that examined visual-spatial abilities have always favored males and have had the largest and most consistent gender differences of any psychometric abilities (Jensen, 1998). The meta-analysis of gender differences in spatial abilities reported by Lynn et al. (2004) showed that boys tend to perform slightly better on average than girls on visualization.

In line with Lynn's developmental theory for gender differences in intelligence (1994, 1999), we observed a male advantage in first graders, which is no longer evident in grades 2 and 3. The results we obtained from our study would be consistent with the assumption of an age-dependent gender difference in CPM, resulting from a male advantage in visualization and visual-spatial abilities due to biological factors in first graders. Alternatively, it might be argued that boys' skills are promoted more in their pre-school environment. However, we included only children that had visited kindergarten before they entered school and only children who were sent to a private school by their parents. This suggests that both boys and girls had a rather favorable and comparable environment in this case, which fostered their development.

\section{Literacy measures}

In this study we investigated the pattern of gender-differences in literacy skills across grades 1 through 3 . What is striking is the male advantage observed in the first grade, which was not evident in the higher grades. Our results are partially consistent with the study of Millar and Barber (1981) in which they found that males made significantly more errors than females while performing a simple spelling task, but there were no significant gender differences in another judgment task that 
emphasized the knowledge of phonological rules related to spelling. Contrary to the dominant view that girls outperform boys in verbal abilities, many studies of typically developing children have not found strong gender differences in reading. Further, Hyde and Linn (1988) conducted a large-scale meta-analysis of studies that examined gender differences in general verbal abilities. They suggest that the overall magnitude of gender differences in these samples is quite small, especially when excluding dyslexic subjects from the analyses. Computerized assessments of literacy skills did not detect the established gender effect, while girls performed better in paper and pencil versions of the same tests (Horne, 2007). Still, the presently observed superiority of male compared to female first graders in literacy skills is somewhat puzzling. It is likely that other abilities that specifically and directly affect literacy acquisition in the Arabic orthography. Notably visualization processing might have contributed to this finding.

Relationship between reading and spelling and the potential role of visualization

Our results showed that the male advantage of first graders in literacy skills might be related to the visuo-spatial abilities as measured by CPM. Similar to Hebrew, which is characterized by the pointing system, predictive correlations were observed between both visual and verbal ability and reading. Again, this suggests the requirement of visuo-spatial processing due to the complexity of the pointing system (Meyler \& Breznitz, 1998). According to Abu-Rabia and Taha (2004), young learners of Arabic suffer from the lack of ability to manipulate GPC rules in their initial stages of acquisition. Consequently, Arabic orthography clearly demands visual word recognition strategies to manipulate change in letter shapes in accordance with its position in a word. This might also explain why the male advantage in literacy skills diminishes in second and third graders, suggesting a decline of the relevance of visual processing in advanced learners and a stronger reliance on GPCs conversion and phonological decoding.

Taken together, our data support a developmental change in the relation between reading and spelling. In first graders, the interdependence between reading and spelling abilities is at least partly mediated by visualization abilities and it therefore enhances the visual-orthographic route (Abu-Rabia \& Taha, 2004). Children's spelling and reading skills diverge soon after the onset of formal instruction (Bosman \& Van Orden, 1997). This is due to the fact that spelling in Arabic requires higher order strategies than accurate word recognition (Azzam, 1993). However, fluent reading requires the development of orthographic strategies.

It is important to note some limitations of our current study. First, it is a cross sectional study, which calls for future longitudinal studies that should further investigate the developmental changes of Arabic-speaking children in literacy skills across different age and grade levels. Moreover, our results on gender differences will need to be replicated in more representative samples with larger numbers of participants. 


\section{References}

Abu Rabia, S. (1995). Learning to read in Arabic: Reading, syntactic, orthographic and working memory skills in normally achieving and poor Arabic readers. Reading Psychology, 16, 351394.

Abu Rabia, S. (1997). Reading in Arabic orthography: The effect of vowels and context on reading accuracy of poor and skilled native Arabic readers in reading paragraphs, sentences, and isolated words. Journal of Psycholinguistic Research, 26, 465482.

Abu Rabia, S. (1998). Reading Arabic texts: Effects of text type, reader type and vowelization. Reading and Writing: Interdisciplinary Journal, 10, 105119.

Abu Rabia, S. (2000). Effects of exposure to literary Arabic on reading comprehension in a diglossic situation. Reading and Writing: An Interdisciplinary Journal, 13, 147157.

Abu Rabia, S. (2001). The role of vowels in reading Semitic scripts: Data from Arabic and Hebrew. Reading and Writing: An Interdisciplinary Journal, 14, 3959.

Abu Rabia, S. (2002). Reading in a root based morphology language: The case of Arabic. Journal of Research in Reading, 25, 299309.

Abu Rabia, S., \& Taha, H. (2004). Reading and spelling error analysis of native Arabic dyslexic readers. Reading and Writing: An Interdisciplinary Journal, 17, 651689.

Allred, R. A. (1990). Gender differences in spelling achievement in grades 1 through 6. Journal of Educational Research, 834, 187193.

Azzam, R. (1993). The nature of Arabic reading and spelling errors of young children. A descriptive study. Reading and Writing: An Interdisciplinary Journal, 5, 355385.

Bosman, A., \& Van Orden, G. (1997). Why spelling is more difficult than reading. In C. A. Perfetti, L. Rieben, \& M. Fayol (Eds.), Learning to spell: Research, theory, and practice across languages (pp. 173 194). Mahwah, NJ: Lawrence Erlbaum.

Chiarello, C., Welcome, S., Halderman, L., Towler, S., Julagay, J., Otto, R., et al. (2009). A large scale investigation of lateralization in cortical anatomy and word reading: Are there sex differences? Neuropsychology, 23, 210222.

Cohen Mimran, R. (2009). The contribution of language skills to reading fluency: A comparison of two orthographies for Hebrew. Journal of Child Language, 36, 657672.

Cotton, S., Kiely, P., Crewther, D. P., Thomson, B., Laycock, R., \& Crewther, S. (2005). A normative and reliability study for the Raven's coloured progressive matrices for primary school aged children from Victoria, Australia. Personality and Individual Differences, 39, 647659.

Ehri, L. (1997). Learning to read and learning to spell are one and the same, almost. In C. A. Perfetti, L. Rieben, \& M. Fayol (Eds.), Learning to spell: Research, theory, and practice across languages (pp. 237 269). Mahwah, NJ: Lawrence Erlbaum.

Ehri, L., \& Wilce, L. (1982). Recognition of spellings printed in lower and mixed case: Evidence for orthographic images. Journal of Literacy Research, 14, 219230.

Elbeheri, G., \& Everatt, J. (2007). Literacy ability and phonological processing skills amongst dyslexic and non dyslexic speakers of Arabic. Reading and Writing: An Interdisciplinary Journal, 20, 273294.

El Hassan, S. (1979). Educated spoken Arabic in Egypt and the Levant: A critical review and related concepts. Archivum Linguisticum, 8, 112132.

Feingold, A. (1988). Cognitive gender differences are disappearing. American Psychologist, 43, 95103.

Frith, U. (1985). Beneath the surface of development dyslexia. In K. Patterson, J. Marshall, \& M. Coltheart (Eds.), Surface dyslexia (pp. 301 330). London, UK: Lawrence Erlbaum.

Hanna, S., \& Greis, N. (1972). Writing Arabic. Leiden, The Netherlands: E. J. BriU.

Horne, J. (2007). Gender differences in computerized and conventional educational tests. Journal of Computer Assisted Learning, 23, 4755.

Hutt, C., \& Hughes, M. (2004). Sex differences in childhood. In R. L. Gregory (Ed.), The Oxford companion to the mind. Oxford, UK: Oxford University Press.

Hyde, J. S., \& Linn, M. C. (1988). Gender differences in verbal ability: A meta analysis. Psychological Bulletin, 104, 5369.

Jensen, A. R. (1998). The g factor: The science of mental ability. Westport, CN: Praeger.

Khaleefa, O., \& Lynn, R. (2008). Normative data for Raven's colored progressive matrices scale in Yemen. Psychological Reports, 103, 170172.

Kimura, D. (1999). Sex and cognition. Cambridge, MA: MIT Press. 
Landerl, K., \& Wimmer, H. (2008). Development of word reading fluency and spelling in a consistent orthography: An 8 year follow up. Journal of Educational Psychology, 100, 150161.

Landerl, K., Wimmer, H., \& Moser, E. (1997). Salzburger Lese und Rechtschreibtest [Salzburg reading and spelling test]. Bern, Switzerland: Hans Huber.

Leppänen, U., Niemi, P., Aunola, K., \& Nurmi, J. (2006). Development of reading and spelling Finnish from preschool to grade 1 and grade 2. Scientific Studies of Reading, 10, 330.

Lerkkanen, M., Rasku Puttonen, H., Aunola, K., \& Nurmi, J. (2004). The developmental dynamics of literacy skills during the first grade. Educational Psychology, 24, 793810.

Lynn, R. (1994). Sex differences in intelligence and brain size: A paradox resolved. Personality and Individual Differences, 17, 257271.

Lynn, R. (1999). Sex differences in intelligence and brain size: A developmental theory. Intelligence, 27, 112.

Lynn, R., Backhoff, E., \& Contreras Niño, L. (2004). Sex differences on g, reasoning and visualization tested by the progressive matrices among 710 year olds: Some normative data for Mexico. Personality and Individual Differences, 36, 779787.

Mackintosh, N. (1998). IQ and human intelligence. Oxford, England: Oxford University Press.

Marsh, G., \& Desberg, P. (1983). Development of strategies in the acquisition of reading. Journal of Reading Behavior, 9, 391394.

May, P. (2002). Hamburger Schreib Probe für die Klassen 5 bis 9, [Hanmbuger Writing Sample Test for class 5 through 9] HSP 59 B. Hamburg, Germany: Verlag für pädagogische Medien.

Meyler, A., \& Breznitz, Z. (1998). Developmental associations between verbal and visual short term memory and the acquisition of decoding skill. Reading and Writing, 10, 519540.

Millar, D., \& Barber, P. (1981). Sex differences in verbal skills: Use of spelling sound and lexical information. Current Psychological Research, 1, 121127.

Moll, K., \& Landerl, K. (2009). Double dissociation between reading and spelling deficits. Scientific Studies of Reading, 13, 359382.

Prefetti, C., \& Hart, L. (2001). The lexical bases of comprehension skill. In D.Gorfien (Ed.), On the consequences of meaning selection (pp. 67 86). Washington, DC: American Psychological Association.

Raven, J. (2000). The Raven's progressive matrices: Change and stability over culture and time. Cognitive Psychology, 41, 148.

Raven, J., Bulheller, S., Court, J., Häcker, H., \& Raven, J. (2006). Coloured progressive matrices mit der parallelform des tests und der puzzle form [Colored progressive matrices, a parallel form of the test and the puzzle form] (3rd ed.). Frankfurt, Germany: Harcourt Test Services.

Richardson, J. (1997). Conclusions. In P. J. Caplan, M. Crawford, J. S. Hyde, \& J. T. E. Richardson (Eds.), Gender differences in cognition. New York: Oxford University Press.

Rutter, M., Caspi, A., Fergusson, D., Horwood, L. J., Goodman, R., Maughan, B., et al. (2004). Sex differences in developmental reading disability: New findings from 4 epidemiological studies. Journal of the American Medical Association, 291, 20072012.

Saiegh Haddad, E. (2003). Linguistic distance and initial reading acquisition: The case of Arabic diglossia. Applied Psycholinguistics, 24, 431451.

Saiegh Haddad, E. (2004). The impact of phonemic and lexical distance on the phonological analysis of words and pseudowords in a diglossic context. Applied Psycholinguistics, 25, 495512.

Saiegh Haddad, E. (2005). Correlates of reading fluency in Arabic: Diglossic and orthographic factors. Reading and Writing: An Interdisciplinary Journal, 18, 559582.

Saiegh Haddad, E. (2007). Linguistic constraints on children's ability to isolate phonemes in Arabic. Applied Psycholinguistics, 28, 605625.

Seymour, P., Aro, M., \& Erskine, J. (2003). Foundation literacy acquisition in European orthographies. British Journal of Psychology, 94, 143174.

Share, D., \& Levin, I. (1999). Learning to read and write in Hebrew. In M. Harris, G. Hatano, M. Harris, \& G. Hatano (Eds.), Learning to read and write: A cross linguistic perspective (pp. 89 111). New York, NY: Cambridge University Press.

Snowling, M. (2000). Dyslexia: A cognitive developmental perspective (2nd ed.). Cambridge, MA: Basil Blackwell.

Stahl, S., Pagnucco, J., \& Suttles, C. (1996). First graders' reading and writing instruction in traditional and process oriented classes. Journal of Educational Research, 89, 131144.

Taouk, M., \& Coltheart, M. (2004). The cognitive processes involved in learning to read in Arabic. Reading and Writing, 17, 2757. 
Thomson, B., Crewther, D., \& Crewther, S. (2006). Wots that werd? Pseudowords (non words) maybe a misleading measure of phonological skills in young learner readers. Dyslexia, 12, 289299.

Willburger, E., \& Landerl, K. (2009). Der Ein Minuten Leseflüssigkeitstest ein Verfahren zur Diagnose der Leistung im Wort und Pseudowortlesen [The one minute Fluent Reading Test a method for the diagnosis of word and pseudoword reading]. Tests und Trends, 7, 6580

Wimmer, H., \& Goswami, U. (1994). The influence of orthographic consistency on reading development: Word recognition in English and German children. Cognition, 51, 91103. 